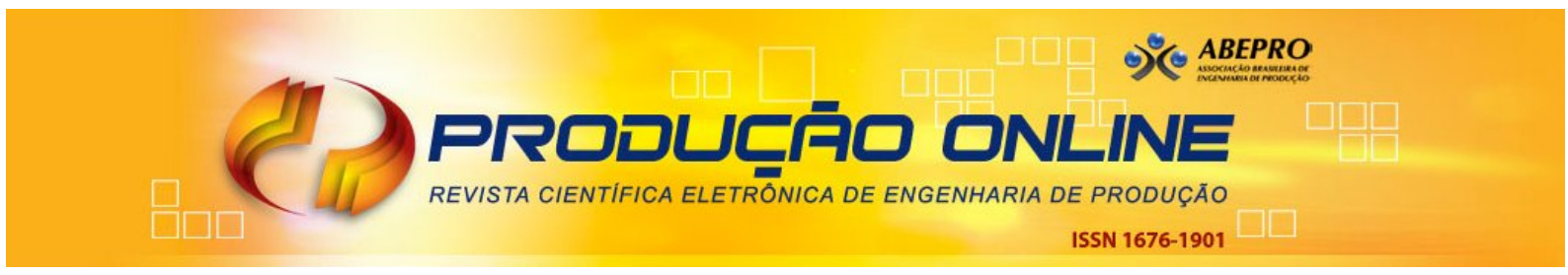

\title{
EVOLUÇÃO DOS ESTUDOS DE LOGÍSTICA REVERSA REALIZADOS NO CONTEXTO NACIONAL: UMA ANÁLISE BIBLIOMÉTRICA
}

\section{EVOLUTION OF REVERSE LOGISTICS STUDIES PERFORMED IN THE BRAZILIAN CONTEXT: A BIBLIOMETRIC ANALYSIS}

\author{
Emmily Caroline Cabral da Fonseca* E-mail: emmilycaroline@hotmail.com \\ Eriton Carlos Martins Barreiros* E-mail: eritonbarreiros@yahoo.com.br \\ André Cristiano Silva Melo*E-mail: acsmelo@yahoo.com.br \\ Denilson Ricardo de Lucena Nunes* E-mail: denilson.lucena@gmail.com \\ Mariana Pereira Caneiro* E-mail: mariana karneiro@yahoo.com.br \\ *Universidade do Estado do Pará (UEPA), Santarém, PA
}

\begin{abstract}
Resumo: A sociedade pós-moderna consome em busca de bem-estar. Para tanto, uma enorme quantidade de recursos naturais é consumida e, consequentemente, grande quantidade de materiais é descartada sob a forma de resíduos. Neste contexto, para tentar minimizar os impactos ambientais, a Lei 12.305/10 instituiu a Política Nacional de Resíduos Sólidos (PNRS), que cumpre o objetivo de promover a destinação ambientalmente adequada aos resíduos sólidos, conferindo grande importância à reciclagem e à responsabilidade compartilhada pelo ciclo de vida do produto, fomentando a criação e manutenção de cooperativas de reciclagem de materiais e as práticas de Logística Reversa (LR). A LR vem ganhando destaque, já que busca soluções holísticas aos problemas ambientais. Desta forma, este artigo tem como objetivo avaliar a evolução de estudos de LR no contexto brasileiro por meio de Análise Bibliométrica de artigos publicados entre os anos de 2010 e 2014. Foi identificado o crescimento no número de publicações que discorrem sobre os temas em questão.
\end{abstract}

Palavras-chave: Logística Reversa. Política Nacional de Resíduos Sólidos. Estudo Bibliométrico.

Abstract: The postmodern society consumes in search of welfare. Therefore, an enormous amount of natural resources is consumed and consequently a large quantity of materials is discarded as waste. In this context, in order to try to minimize the environmental impacts, the Law 12.305/10 was approved, which established the National Policy for Solid Waste (PNRS). This policy comprises the objective of promoting the environmentally appropriated disposal of solid waste, assigning great importance to the recycling process and the shared responsibility for product lifecycle, which encouraged the creation and maintenance of recycling cooperatives of materials and Reverse Logistic $(\mathrm{RL})$ practices. The $\mathrm{RL}$ has been highlighted since it seeks for holistic solutions for environmental problems. Hence, this study aimed to evaluate the evolution of Brazilian RL studies through a Bibliometric Analysis which comprehended articles published between 2010 and 2014. The growth in the number of publications that discuss the referred topics was substantiated.

Keywords: Reverse Logistics. National Policy of Solid Waste. Bibliometric Study.

\section{INTRODUÇÃO}

O aumento do consumo na sociedade atual é notório. Como consequência uma enorme quantidade de recursos naturais é consumida e, ao final, grandes quantidades ainda são descartadas sob a forma de resíduos (NOVAES e SILVA, 
2013). A crescente geração de resíduos demanda uma série de ações, como manipulação, tratamento e descarte adequado desses residuos, de maneira a evitar problemas ambientais. Em muitas situações, a motivação para tratamento e descarte adequados dos resíduos surge na forma de imposição legal, pois é o aumento destas exigências que faz produtores e consumidores se adequarem e buscarem novas estratégias de resolução dos problemas ambientais (ALMEIDA, 2013).

Com o intúito de minimizar os impactos ambientais resultantes da destinação dos resíduos, segundo Novaes e Silva (2013), a Lei 12.305/10, que instituiu a Política Nacional de Resíduos Sólidos (PNRS), orienta a destinação ambientalmente adequada aos resíduos sólidos, conferindo grande papel à reciclagem, à responsabilidade compartilhada pelo ciclo de produto, ao fomento a criação e manuntenção de cooperativas de catadores de materiais recicláveis e à prática da Logística Reversa (LR). Segundo a PNRS (BRASIL, 2010a), a LR é definida como:

Instrumento de desenvolvimento econômico e social caracterizado por um conjunto de ações, procedimentos e meios destinados a viabilizar a coleta e restituição dos resíduos sólidos ao setor empresarial, para reaproveitamento, em seu ciclo ou em outros ciclos produtivos, ou outra destinação final ambientalmente adequada.

Portanto, o exercício das atividades de LR nas empresas deve se adequar às exigências legais, sobretudo porque os prazos, definidos pela Lei, para implementação de soluções à destinação adequada dos resíduos, pelos municípios em todo território nacional, venceram em agosto de 2014. A partir daí, o Estado considera que empresas, públicas ou privadas, se encontram em desconformidade, podendo resultar em complicações legais para estas. Por outro lado, a adequação legal às práticas de LR não é tarefa simples, pois segundo Leite (2012), seu uso é recente nas organizações, tendo início a partir da segunda metade do século $X X$, com atividades, conceitos e modelos de operação, ainda em pleno desenvolvimento. Em virtude da urgência em atender à Lei, torna-se relevante compreender como a Engenharia de Produção, a partir da evolução de sua produção científica pertinente a teoria e prática de LR à luz da PNRS, vem formalizando conhecimento capaz de direcionar ações sustentáveis para melhor gestão dos resíduos.

Assim, este estudo teve como objetivo avaliar a evolução dos estudos de LR no Brasil, considerando aspectos relacionados ao contexto atual de implementação da PNRS, por meio da Análise Bibliométrica, definida por Araújo (2006, p.13) como 
uma prática voltada para estudos de artigos de periódicos e outros formatos de produção bibliográfica que permite ao pesquisador conhecer uma série de padrões acerca do campo estudado, como tamanho e características dos acervos pesquisados. Para que alguns padrões referentes a processos de LR pudessem ser identificados, realizou-se a análise de artigos publicados entre 2010 e 2014 sobre esse tema.

A base de dados pesquisada foi composta por: dois anais de eventos nacionais, Simpósio de Engenharia de Produção (SIMPEP) e o Encontro Nacional de Engenharia da Produção (ENEGEP), por serem os dois maiores eventos da área de Engenharia de Produção no Brasil; e cinco periódicos da mesma área, a Revista Gestão da Produção, Operação e Sistemas (GEPROS), por estar associado ao mesmo grupo que organiza o SIMPEP (FEB/UNESP); a Revista Produção Online e o Brazilian Journal of Operations \& Production Management (BJO\&PM), por possuírem o selo de periódicos da Associação Brasileira de Engenharia de Produção (ABEPRO), além das revistas Produção (Impresso) e Gestão \& Produção, por serem periódicos da área de Engenharia de Produção considerados na lista da SCIELO (Scientific Electronic Library Online) e por serem muito bem qualificados no QualisPeriódicos da Capes (Qualis B2 - Engenharias III).

Foram coletados 136 artigos, publicados no intervalo predefinido, nas bases de dados digitais disponíveis nas páginas eletrônicas dos eventos e dos periódicos considerados, correspondendo à busca das seguintes palavras-chave: Logística Reversa e Reverse Logistics, as quais foram verificadas entre título, resumo e palavras-chave, conforme as ferramentas de busca disponíveis. A análise dos dados foi feita com o auxilio do software MS Excel que permitiu apresentar os dados de forma simplificada.

Os artigos foram analisados com o propósito de avaliar a evolução dos estudos de LR no Brasil, originados a partir da área de Engenharia de Produção, considerando os últimos 5 anos, bem como o seu encadeamento com o contexto atual de implementação da PNRS, e, para tal, foi proposta a seguinte questão de pesquisa: Em virtude do contexto atual de implementação da PNRS no Brasil, qual o estágio atual de evolução das últimas pesquisas brasileiras em LR, desenvolvidas na área de engenharia de produção? Para responder a tal questão, algumas questões foram propostas, como base para as análises efetuadas neste estudo. 
À vista disso, os dados foram organizados e analisados, resultando em 2 contribuições específicas, a saber: a identificação das tendências dos estudos de LR já desenvolvidos na Engenharia de Proddução; e a identificação de oportunidades para desenvolvimento de novas pesquisas de LR em áreas relacionadas à Engenharia de Produção, em especial Logística. Desta forma, o artigo foi organizado em: revisão bibliográfica, procedimentos metodológicos, resultados e discussões sobre os dados levantados, e considerações finais.

\section{LOGÍSTICA REVERSA}

Ultimamente, a preocupação com o meio ambiente, aliado à racionalização do uso dos recursos, tem recebido atenção especial. Em função disso é que ações de LR têm ganhado espaço entre empresas e entre adeptos do uso racional de matériaprima e dos demais recursos que podem passar por processos de reaproveitamento (CRUZ et al., 2013).

O princípio de responsabilidade compartilhada pelo ciclo de vida dos produtos está relacionado às empresas a partir do conceito de LR (ABRELPE, 2013, p.52). Assim, segundo Andrade (2013), fabricantes passam a ter responsabilidade pelo produto além de seus limites organizacionais, quer para reciclagem quer para descarte ambientalmente correto. A Associação Brasileira de Empresas de Limpeza Pública e Resíduos Especiais - Abrelpe (ABRELPE, 2013, p.52) defende que a LR é considerada um marco da PNRS, segundo a qual quando um produto chega ao final de sua vida útil é devolvido ao fabricante ou ao importador, para reciclagem ou outro tratamento apropriado.

Nesse âmbito, a PNRS cita, em seu Capítulo III, seção II, Art.33, a obrigatoriedade de estruturação e implementação de sistemas de LR, para retorno de resíduos de pós-consumo/produção, independentemente do serviço público de limpeza urbana e de manejo dos resíduos sólidos, aos fabricantes, importadores, distribuidores e comerciantes de:

I- Agrotóxicos, seus resíduos e embalagens, assim como outros produtos cuja embalagem, após o uso, constitua resíduo perigoso, observadas as regras de gerenciamento de resíduos perigosos previstas em lei ou regulamento, em normas estabelecidas pelos órgãos do Sisnama, do SNVS e do Suasa, ou em normas técnicas; 
II- Pilhas e baterias;

III- Pneus;

IV- Óleos lubrificantes, seus resíduos e embalagens;

V- Lâmpadas fluorescentes, de vapor de sódio e mercúrio e de luz mista;

VI- Produtos eletrônicos e seus componentes.

$\S 11^{0}$ : Na forma do disposto em regulamento ou em acordos setoriais e termos de compromisso firmados entre o poder público e o setor empresarial, os sistemas previstos serão estendidos a produtos comercializados em embalagens plásticas, metálicas ou de vidro, e aos demais produtos e embalagens, considerando, prioritariamente, o grau e a extensão do impacto à saúde pública e ao meio ambiente dos resíduos gerados (BRASIL, 2010a).

Este Parágrafo da PNRS pode ter influenciado os resultados levantados pelo Panorama dos Resíduos Sólidos no Brasil de 2013, onde quatros setores industriais - alumínio, papel, plástico e vidro - já possuem considerável participação nas atividades de reciclagem no país (ABRELPE, 2013, p.35) e a estas possivelmente algum canal reverso deve ter sido associado.

O Reverse Logistics Executive Council - RLEC define a LR como sendo o processo de movimentação de mercadorias do seu destino final típico para outro ponto, com o objetivo de obter valor de outra maneira indisponível, ou com o objetivo de efetuar a disposição final dos produtos (RLEC, 2014).

Já Leite (2003) entende a LR como a área da logística empresarial que planeja, opera e controla o fluxo e as informações correspondentes, do retorno dos bens de pós-venda e de pós-consumo ao ciclo produtivo, por meio dos canais de distribuição reversos, agregando-Ihes valor de diversas naturezas: economico, ecológico, de imagem corporativa, entre outros.

Segundo o mesmo autor, a LR pode ser subdivida em pós-consumo e pósvenda. A primeira caracteriza-se por iniciar somente após a finalização do ciclo de vida útil do bem, enquanto a segunda, é efetivada após o material ser definido com pouco ou nenhum uso, o qual, por diferentes motivos, retorna aos diferentes elos da cadeia direta.

De acordo com Guarnieri (2011), a LR inicia suas operações no exato momento em que a logística direta encerra as suas, pois após a entrega do produto ao cliente final são gerados materiais que necessitam ser reinseridos ao ciclo produtivo ou de negócios, possibilitando a formação de um ciclo logístico fechado. 
Caso contrário, se o produto for reinserido em um ciclo produtivo distinto do seu original, um ciclo logístico aberto é caracterizado.

Embora utilizando as mesmas técnicas e ferramentas da logística direta, por tratar do retorno de produtos, a LR tem sua atividade relacionada à satisfação dos clientes, com garantia de sustentabilidade empresarial. Empresas estrategicamente perspicazes percebem o seu impacto no relacionamento com clientes e com o público em geral, pelo reflexo de sua imagem (LEITE, 2014). As empresas que já utilizam a LR têm vantagem competitiva, já que os consumidores começam a preferir produtos com apelo à sustentabilidade e responsabilidade social (DRUWE, 2014).

Entre as dificuldades à implementação da LR, comparando-a com a cadeia direta, tem-se recebimentos de materiais variados, operações de coleta e irregularidades do retorno. Considera-se um grande desafio o retorno dos bens ao local de reciclagem ou de disposição final adequada (ANDRADE, 2013).

Porém, na prática, algumas atividades de LR já ocorrem informalmente em muitas empresas, mesmo desconhecendo o seu conceito, devido à necessidade de dar destino aos resíduos para cumprir a legislação (GUARNIERI, 2011). De uma forma geral, os desafios da LR são relevantes pelas características dos produtos retornados e pelas suas condições gerais de heterogeneidade, que determinam soluções logísticas adequadas a cada caso (LEITE, 2014a). Fato que desistimula as empresas a adotar as práticas de LR em seus processos.

\section{POLÍTICA NACIONAL DE RESÍDUOS SÓLIDOS}

A Política Nacional de Resíduos Sólidos - PNRS, aprovada na Câmara Federal, em 11 de março de 2010 e, em 7 de julho, no Senado Federal, com sanção presidencial em 2 de agosto de 2010, reúne o conjunto de princípios, objetivos, instrumentos, diretrizes, metas e ações adotados pelo Governo Federal, isoladamente ou em regime de cooperação com Estados, Distrito Federal, Municípios ou particulares, com vistas à gestão integrada e ao gerenciamento ambientalmente adequado dos resíduos sólidos (BRASIL, 2010b).

Faria (2012) sustenta que a Lei trouxe inovações referentes à introdução de novos conceitos, como o de LR, Responsabilidade compartilhada pelo ciclo de vida do produto, a diferenciação entre resíduo sólido e rejeito, entre destinação final e disposição final, entre outros. E prossegue o comentário ao explicitar que:

Revista Produção Online, Florianópolis, SC, v.15, n. 4, p. 1457-1480, out./dez. 2015. 
Este novo cenário introduziu uma mudança de paradigma com relação ao conceito de ciclo de produção. Antes encarado como em cadeia aberta (linear), encerrado no recebimento do produto pelo consumidor, agora há uma nova tendência em considera-lo como em cadeia fechada (cíclica), ou seja, o seu "fim", ou recomeço, ocorre com o reaproveitamento do resíduo gerado no conjunto pela cadeia produtiva. Fato este que se dá precipuamente em virtude das mudanças trazidas pela PNRS.

Para Granziera (2011, p.297), a Lei trata basicamente de duas abordagens: a poluição e os impactos ambientais ocasionados por resíduos sólidos, e o consumo sustentável, que implica na adoção de padrões sustentáveis de produção e consumo de bens e serviços, e na responsabilidade compartilhada pelo ciclo de vida do bem.

De acordo com Lira (2010), esta Política leva em consideração os graves problemas causados ao meio ambiente, a partir da disposição final inadequada dos resíduos sólidos, pois, mesmo sendo fabricados a partir dos recursos naturais, muitos não são possíveis de serem degradados pela natureza, devido ao alto grau de transformação e processamentos a que as matérias-primas foram submetidas.

Nesse âmbito, com o objetivo de manter os atuais patamares de geração de resíduos sólidos com posterior redução, a PNRS propõe estratégias, como reciclagem, reaproveitamento, redução da quantidade de resíduos sólidos gerados durante a produção, incentivo à rotulagem ambiental, eliminação de lixões e aterros controlados e, finalmente, a análise do ciclo de vida, que mapeia o processo de produção do objeto, que possibilitam destinação adequada por meio de sua interpretação (BRASIL, 2010a).

Segundo Freire (2010), é pertinente ressaltar que a divisão de responsabilidades sobre a gestão dos resíduos na regulação da PNRS, ultrapassa o setor público e chega ao setor privado e à sociedade como um todo, trazendo inovações para empresas e empreendimentos privados, alterando a conduta empresarial e estabelecendo mudanças operacionais.

Porém a gestão integrada dos resíduos sólidos é sistêmica e contempla aspectos institucionais, administrativos, financeiros, ambientais, sociais, técnicooperacionais e políticos, o que a caracteriza como atividade complexa e sustentada por relações de poder históricas e difíceis de serem enfrentadas (ARAÚJO, 2011). Nesse contexto, a PNRS diverge as responsabilidades quanto à citada gestão, tornando-se um desafio aos municípios, mas também para os estados, Distrito Federal e, principalmente, à iniciativa privada como um todo (BRASIL, 2010a). 


\section{PROCEDIMENTOS METODOLÓGICOS}

De acordo com classificação proposta Gupta et al. (2006), esta pesquisa foi caracterizada uma pesquisa de dados secundários, pois envolveu a compilação de dados oriundos de fontes de informação, sendo utilizados anais de congressos e bases de periódicos. Assim, foram realizadas as seguintes etapas de pesquisa:

\subsection{Definição dos parâmetros da análise bibliométrica}

Foram determinados os termos de pesquisa, base de dados e período analisado. A base de dados foi formada a partir da visita aos sites e coleta de artigos relacionados ao tema "Logística Reversa" ou "Reverse Logistics", relacionados aos 2 maiores eventos nacionais de engenharia de produção (Simpósio de Engenharia de Produção - SIMPEP e Encontro Nacional de Engenharia da Produção - ENEGEP) e a 5 periódicos da mesma área, a saber: Gestão da Produção, Operação e Sistemas (GEPROS), por estar associado ao mesmo grupo que organiza o SIMPEP (FEB/UNESP); Produção Online e Brazilian Journal of Operations \& Production Management (BJO\&PM), por possuírem o selo de periódicos da Associação Brasileira de Engenharia de Produção (ABEPRO); e Produção (Impresso) e Gestão \& Produção, por serem periódicos da área considerados na lista da SCIELO (Scientific Electronic Library Online) e por estarem bem qualificados no QualisPeriódicos da Capes (Qualis B2 - Engenharias III), considerando, como período analisado, os últimos 5 anos de produção bibliográfica (2010 - 2014), tendo em vista que buscou-se visualizar um cenário do avanço dos estudos de LR publicados já no contexto de implementação da PNRS.

\subsection{Busca e leitura dos artigos}

Definidos os parâmetros, foi feita a busca e leitura integral dos artigos, a partir da qual foram identificadas as respostas para as indagações propostas, referentes à Abordagem Específica do problema. Além disso, a amostra coletada foi organizada de modo que a simplificação do entendimento fosse alcançada.

\subsection{Tabulação e análise dos dados}

Revista Produção Online, Florianópolis, SC, v.15, n. 4, p. 1457-1480, out./dez. 2015. 
Os dados foram tabulados e organizados em tabelas e gráficos, e correspondem às respostas de 6 questões, propostas a partir da questão de pesquisa, a saber: 1) O enfoque de LR considerado extrapola os limites organizacionais da empresa em estudo?; 2) A PNRS é citada no estudo?; 3) Quais materiais envolvidos na LR são abordados no artigo?; 4) Quais os ganhos (Ambientais, Econômicos ou Sociais) obtidos com a(s) prática(s) de LR destacadas no artigo?; 5) Quantos artigos tratam a LR de pós-venda e quantos tratam a LR de pós-consumo?; 6) Quantos artigos abordam a LR de ciclo aberto e quantos abordam a LR de ciclo fechado?. Tais perguntas e seus objetivos de pesquisa estão relacionados no Quadro 1.

Quadro 1- Questões propostas e seus respectivos objetivos de pesquisa

\begin{tabular}{|l|l|}
\hline \multicolumn{1}{|c|}{ Questões Propostas } & \multicolumn{1}{c|}{ Objetivos de Pesquisa } \\
\hline $\begin{array}{l}\text { 1) O enfoque de LR considerado extrapola os } \\
\text { limites organizacionais da empresa em estudo? }\end{array}$ & $\begin{array}{l}\text { Identificar se o Princípio de Responsabilidade } \\
\text { Compartilhada, proposto pela PNRS, está } \\
\text { sendo seguido; }\end{array}$ \\
\hline 2) A PNRS é citada no estudo? & $\begin{array}{l}\text { Identificar a frequência com que a Lei é citada, } \\
\text { para verificar se esta vem exercendo influência } \\
\text { sobre os estudos publicados após o seu ano de } \\
\text { vigência; }\end{array}$ \\
\hline $\begin{array}{l}\text { 3) Quais materiais envolvidos na LR são } \\
\text { abordados no artigo? }\end{array}$ & $\begin{array}{l}\text { Identificar se os materiais citados pela Lei estão } \\
\text { sendo os mais estudados; }\end{array}$ \\
\hline $\begin{array}{l}\text { 4) Quais os ganhos (Ambientais, Econômicos } \\
\text { ou Sociais) obtidos com a(s) prática(s) de LR } \\
\text { destacadas no artigo? }\end{array}$ & $\begin{array}{l}\text { Identificar a visão que literatura vem destacando } \\
\text { a respeito dos ganhos obtidos com a PNRS; }\end{array}$ \\
\hline $\begin{array}{l}\text { 5) Quantos artigos tratam a LR de pós-venda e } \\
\text { quantos tratam a LR de pós-consumo? }\end{array}$ & $\begin{array}{l}\text { Avaliar a frequência com que estudos e práticas } \\
\text { das 2 abordagens de LR têm sido relatados na } \\
\text { literatura; }\end{array}$ \\
\hline $\begin{array}{l}\text { 6) ) Quantos artigos abordam a LR de ciclo } \\
\text { aberto e quantos abordam a LR de ciclo } \\
\text { fechado? }\end{array}$ & $\begin{array}{l}\text { Identificar qual destinação tem frequentemente } \\
\text { sido dada aos resíduos abordados na literatura. }\end{array}$ \\
\hline
\end{tabular}

Fonte: Autores (2015)

\section{RESULTADOS E DISCUSSÕES}

$\mathrm{Na}$ Tabela 1 são apresentados os artigos analisados neste trabalho. De acordo com esta, o número de artigos publicados em congressos foi 119 , sendo o ENEGEP (60) o detendor da maioria deles. Porém a diferença entre ele e SIMPEP (59) foi de apenas um artigo. Porém, ressalta-se que o número de publicações no SIMPEP é relativamente constante, desde o ano de 2010, ao contrário do ENEGEP que começou a publicar artigos relativos à LR somente nos últimos 3 anos.

Tabela 1 -Distribuição dos artigos de acordo com o evento/periódico considerado 


\begin{tabular}{|c|c|c|c|c|c|c|c|c|}
\hline $\begin{array}{l}\text { Evento ou } \\
\text { periódicol } \\
\text { ano }\end{array}$ & SIMPEP & ENEGEP & GEPROS & $\begin{array}{l}\text { Gestão \& } \\
\text { Produção }\end{array}$ & $\begin{array}{c}\text { Produção } \\
\text { Online }\end{array}$ & Produção & $\begin{array}{c}\text { BJO\& } \\
\text { PM }\end{array}$ & Total \\
\hline 2010 & 10 & 0 & 1 & 0 & 0 & 0 & 1 & 12 \\
\hline 2011 & 10 & 0 & 1 & 0 & 1 & 1 & 0 & 13 \\
\hline 2012 & 6 & 21 & 0 & 1 & 1 & 0 & 0 & 29 \\
\hline 2013 & 8 & 18 & 1 & 1 & 2 & 1 & 0 & 31 \\
\hline 2014 & 25 & 21 & 2 & 0 & 2 & 1 & 0 & 51 \\
\hline Total & 59 & 60 & 5 & 2 & 6 & 3 & 1 & 136 \\
\hline
\end{tabular}

Fonte: Autores (2015)

Em relação aos periódicos, o total coletado foi 17 artigos, número aparentemente pequeno, para um período de 5 anos, mas natural, uma vez que são lançadas poucas edições ao ano. A revista com o maior número de artigos no período considerado foi a Produção Online, totalizando 6 artigos (CARVALHO, FIORAVANTI e JUNIOR, 2011; MAGNAGO, AGUIAR e PAULA, 2012; RAMALHO e SELLITTO, 2013; NETO e CARMO, 2013; TENÓRIO, SILVA e DACORGO, 2014; BARBIERI et al., 2014).

A partir da Tabela 1, percebe-se o crescimento no número de publicações, com 2014 representando $37,2 \%$ do percentual da amostra, com crescimento de $14,6 \%$ quando comparado ao ano anterior. Fato positivo, em virtude dos estudos em LR serem considerados ainda escassos no Brasil.

A seguir, cada questão considerada é melhor justificada e os resultados gerados, a partir das aplicações na amostra considerada, são apresentados.

Questão 1: O enfoque de Logística Reversa considerado extrapola os limites organizacionais da empresa em estudo?

A Questão 1 foi elaborada com o intuito de observar o atual estado das práticas de LR nos artigos coletados, no contexto das empresas e seus elos na cadeia de suprimentos. A importância da identificação desses elos advém do Princípio de Responsabilidade Compartilhada, proposto pela PNRS, que constitui um conjunto de atribuições individualizadas e encadeadas por todos os elos envolvidos no ciclo de vida do produto. Logo, a empresa que impulsiona as práticas de LR para além dos limites organizacionais pode estar seguindo este princípio mesmo que, em muitos casos, de forma não proposital.

Assim, observa-se no Gráfico 1 que, na maioria dos artigos analisados, o exercício da LR não extrapola os limites internos da empresa, com 52,20\% da 
amostra, fato que não cumpre o quesito de Responsabilidade Compartilhada, instituido pela PNRS, onde outros os elos devem participar de práticas que favoreçam o equilíbrio do meio ambiente de forma integrada. Fato que condiz com os resultados obtidos com o levantamento feito por Dias, Labegalini e Csillag (2012, p.526), que evidenciaram, por meio de comparações entre publicações nacionais e internacionais, que há dificuldades na estruturação da cadeia de LR, no que diz respeito à interação dos atores envolvidos.

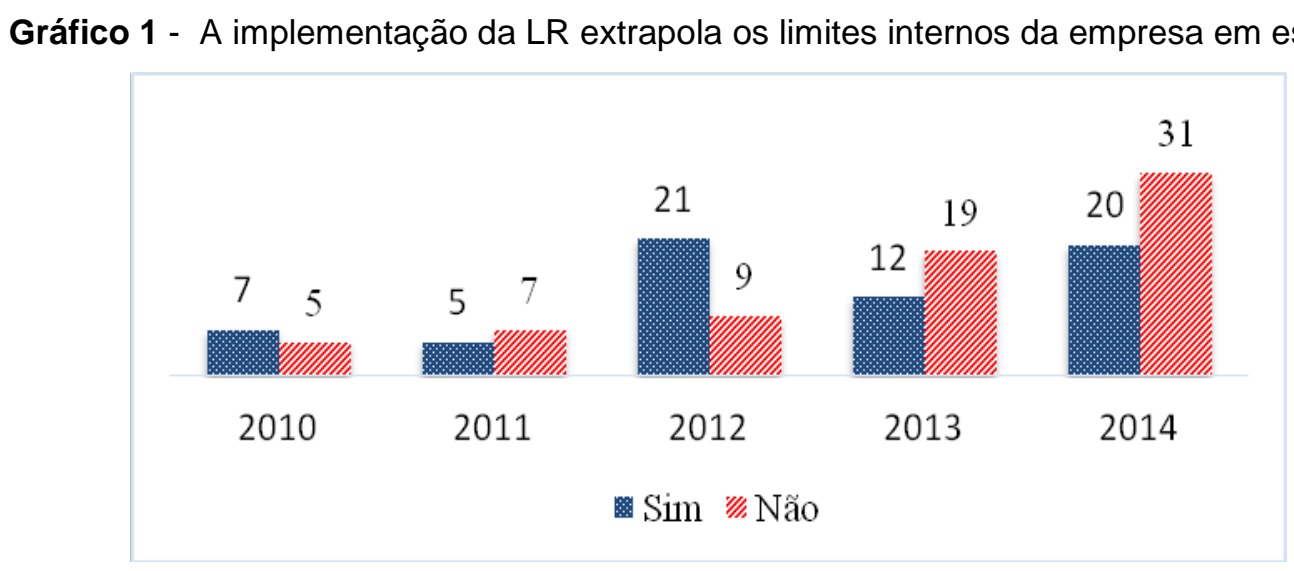

Fonte: Autores (2015)

Desta forma, pesquisas sobre oportunidades de identificação e integração dos elos, e consolidação dos canais reversos, via desenvolvimento de ações conjuntas (parcerias) de LR, abordando temas como Gerenciamento da Cadeia de Suprimentos Reversa (Reverse Supply Chain Management - RSCM) e Gestão Integrada de Resíduos Sólidos (GIRS), podem auxiliar a superar tais dificuldades, contribuindo para formalização do Princípio de Responsabilidade Compartilhada, proposto pela PNRS.

Contudo, nos estudos onde as práticas extrapolam os limites internos (47,80\%), a maior frequência ocorreu entre empresas geradoras de resíduos sólidos e empresas que desenvolvem reciclagem ou reutilização (22\%), tanto na LR de pósvenda quanto na de pós-consumo, atividades que visam a estabelecer maior equilíbrio entre meio ambiente e unidades geradoras de resíduos. Com isso, é possível diminuir custos, uma vez que essas propiciam oportunidades para reuso, permitindo que futuras gerações usufruam dos mesmos recursos.

Questão 2: A Política Nacional de Resíduos Sólidos é citada no estudo? 
A Questão 2 foi criada com a finalidade de verificar o quanto a PNRS está dinfudida nos estudos em análise, uma vez que a amostra foi coletada desde o primeiro ano de vigência da Lei (2010), além de relevar se esta tem influenciado decisões e operações nas organizações. Percebe-se, no Gráfico 2, que 56,60\% dos artigos não citam a PNRS e no ano de sua instituição, 2010, não houve nenhum estudo a respeito, o que é natural que aconteça, já que a Lei foi proposta neste mesmo ano. Porém, um relativo crescimento é notado com o passar dos anos.

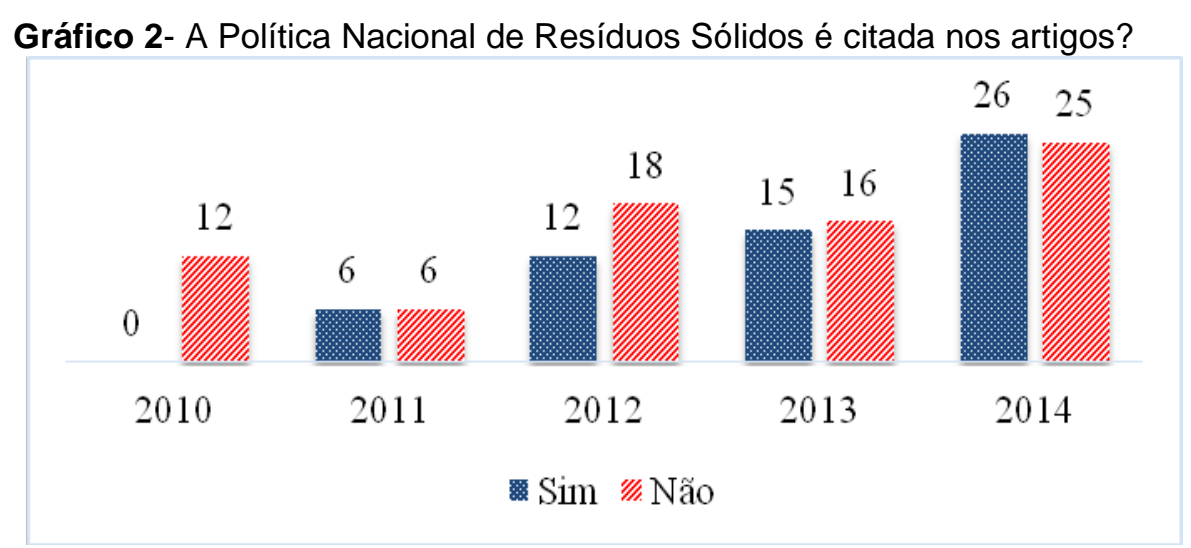

Fonte: Autores (2015)

Além disso, ressalta-se que por mais que muitos artigos tenham citado a PNRS, sua influência foi considerada baixa, já que a maior parte das citações foram feitas no referencial teórico, tendo pouco ou nenhum domínio sobre a condução dos estudos. Nesse âmbito, ressalta-se que a PNRS, de acordo com Silva e Barros (2012), inicialmente foi vista como o primeiro passo para solucionar o problema dos resíduos sólidos, porém, passados mais de quatro anos de sua aprovação, sua influência ainda é baixa sobre o desenvolvimento de estudos brasileiros, sobretudo associados à Engenharia de Produção. Assim, espera-se que, além de citações na teoria, a PNRS seja direcionadora ao desenvolvimento de pesquisas voltadas à proposição de novas abordagens e estratégias de LR.

Questão 3: Quais materiais envolvidos na LR são abordados no artigo?

Em concordância com o Art. 33 do terceiro capítulo da Lei 12.305/10, seis classes de materiais foram definidas para serem analisadas no estudo, de modo a verificar se os artigos coletados consideram materiais entre aqueles em que a Lei prevê cuidados especiais por todos os elos envolvidos em sua cadeia. 
Para a identificação dos materiais mais presentes nos estudos, oito classes foram consideradas, a saber: Agrotóxicos/resíduos/embalagens; Pilhas/Baterias; Pneus; Óleos lubrificantes/resíduos/embalagens; Lâmpadas (fluorescentes, vapor de sódio e de mercúrio, e mista), Eletroeletrônicos; Geral; e Outros), que foram organizadas nos Gráficos 3 e 4, para facilitar a apresentação dos resultados. Ressalta-se que a classe Geral foi considerada em artigos que não citam, de forma específica, nenhum material, sendo suas práticas e propostas apresentadas de forma mais abrangente para resíduos sólidos. Já na classe Outros, enquadraram-se os artigos cujos resíduos considerados não foram citados na Lei 12.305/10, e que podem, ou não, ter um destino diferente, como os Resíduos de Saúde.

Um exemplo de material que merece extremo cuidado e conhecimento sobre os perigos que oferece, sãos as embalagens de óleos lubrificantes que, para retornarem ao ciclo produtivo, devem passar por diversas etapas que favoreçam à descontaminação do material, a qual, por sua vez, não deve ser feita de qualquer modo e também necessita de conhecimentos específicos, para que seja considerada uma prática ambientalmente correta, por isso a Lei cita que o manuseio desse tipo de material deve estar em conformidade com suas leis específicas. No Gráfico 3, onde foram consideradas as classes Agrotóxicos/resíduos/embalagens, Pilha/Bateria, Pneus e Óleo lubrificante/resíduos/embalagens, demonstra-se que o menor número de estudos foram os que trataram de Pneus, com 4,41\%, com as demais classes apresentando 5,15\% cada.

Gráfico 3 - Quais materiais envolvidos na LR são abordados no artigo?

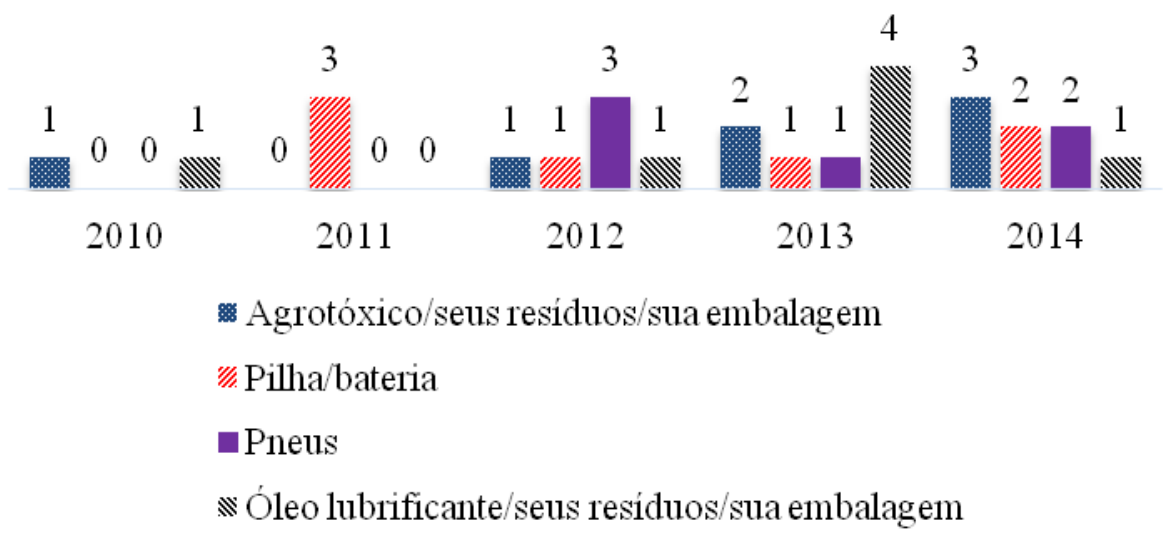

Fonte: Autores (2015)

Revista Produção Online, Florianópolis, SC, v.15, n. 4, p. 1457-1480, out./dez. 2015. 
No Gráfico 4, que considerou as classes Lâmpadas (flourescentes, vapor de sódio e de mercúrio e luz mista), Eletroeletrônicos, Geral e Outros, obteve-se a classe Geral com o maior percentual $(32,40 \%)$, onde os estudos não trataram as práticas de LR especificamente para cada classe de material, e sim, citaram as macroatividades envolvidas nos processos, como coleta, processamento e entrega.

Para a classe Outros, foram publicados 41 artigos (30,20\%), somatório aparentemente relevante, porém, constatou-se que tais artigos tratavam de materiais não contemplados no parágrafo que a Lei propõe a responsabilidade compartilhada entre os elos envolvidos no ciclo de vida dos produtos. Entre estes materiais, destacaram-se os resíduos da Construção Civil, Hospitalares e Orgânicos.

Gráfico 4 - Quais materiais envolvidos na LR são abordados no artigo?

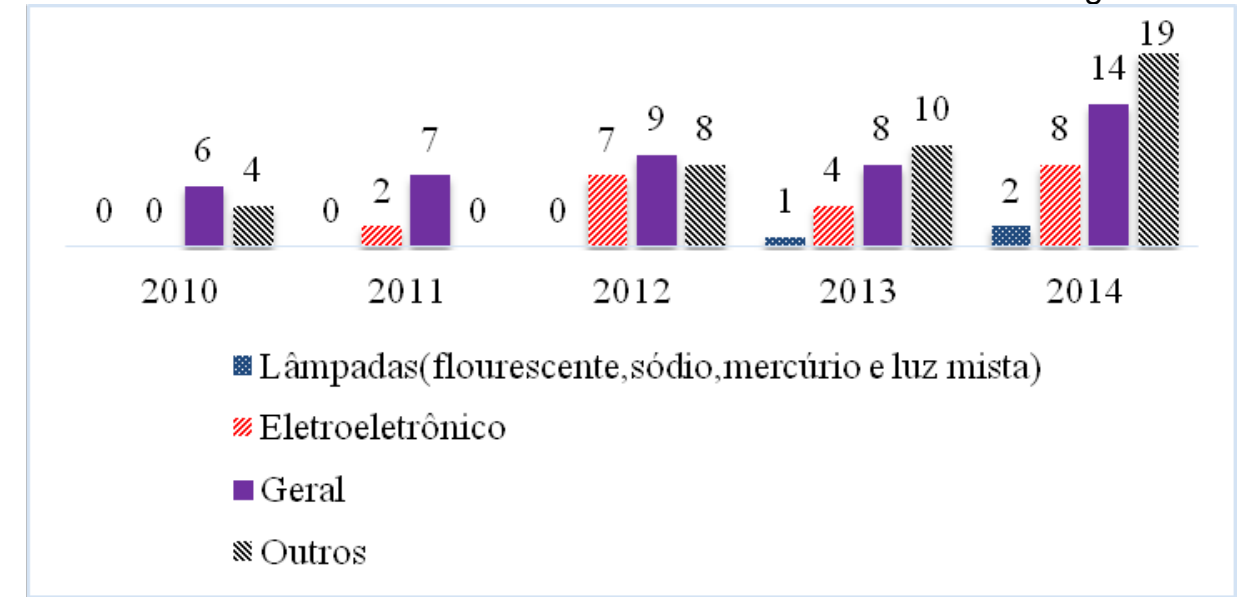

Fonte: Autores (2015)

Desta forma, mesmo após mais de 4 anos de vigência da PNRS, as classes de materiais definidas nesta Lei, aparentemente, ainda se fazem pouco presentes em estudos de LR e tal ausência pode ser consequência da baixa viabilidade econômica destes materiais que, em vários contextos, é considerada a "mola propulsora" para estruturação dos canais reversos. Isto pode ser fruto principalmente do baixo nível de dispersão tecnológica, associado à reutilização ou reciclagem dos resíduos provenientes destas classes, que faz com que as distâncias entre os pontos de geração (fornecedores) e de remanufatura/reciclagem desses materiais (clientes) sejam muito grandes. No caso dos Eletroeletrônicos, por exemplo, os pontos de remanufatura/reciclagem estão, praticamente, todos concentrados na região sudeste do país. 
Assim, para promover a viabilidade econômica necessária à estruturação de canais reversos desses materiais, deve-se desenvolver pesquisas, por exemplo, considerando políticas públicas de incentivos ao aumento tanto da dispersão tecnológica, por meio da instalação de novos pontos de remanufatura/reciclagem, mais próximos aos pontos de geração, como do fluxo dos resíduos até os atuais pontos de remanufatura/reciclagem, por meio da redução de tributos associados a serviços logísticos com viés de sustentabilidade.

Questão 4: Quais os ganhos (Ambientais, Econômicos ou Sociais) obtidos com a(s) prática(s) de LR destacadas no artigo?

Com a Questão 4, pode-se constatar a visão de autores e das organizações objetos de estudos, entre os artigos considerados na amostra, em relação ao claro entendimento de que a PNRS favorece ganhos em sustentabilidade (econômico, social e ambiental) resultantes de práticas que envolvem a LR.

Com o Gráfico 5 percebe-se que os artigos consideraram o ganho ambiental como o mais relevante, com $25,70 \%$ da amostra. Fato considerado negativo, pois reflete uma cultura organizacional que foca somente um ganho, quando o ideal seria explorar cada vez mais simultaneamente os outros benefícios potencializados pela PNRS, por exemplo, ao definir o desenvolvimento sustentável (ganho ambiental, social e econômico) como um dos seus princípios, além da GIRS sólidos e o estímulo à adoção de padrões sustentáveis de produção e consumo de bens e serviços, como alguns de seus objetivos. Com base nos dados coletados, percebeuse uma modesta influência da PNRS nas pesquisas, principalmente no sentido de proporcionar aos "elos" maior compreenção sobre posicionamentos e funções nas cadeias de suprimentos, e ganhos a partir de práticas sustentáveis, como a LR.

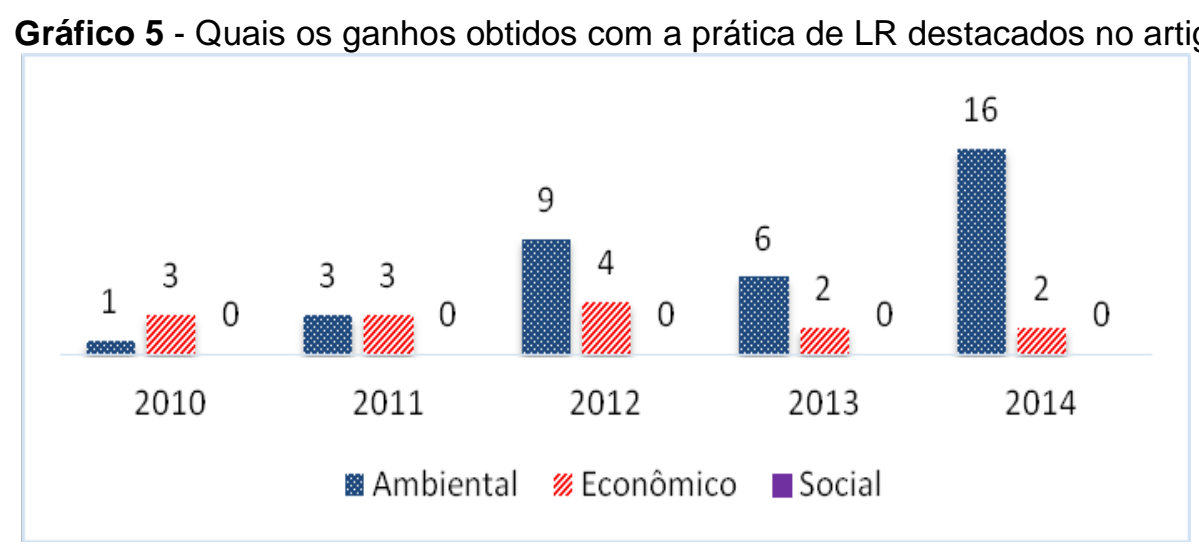


Fonte: Autores (2015)

Por exemplo, no trabalho feito por Araújo et al. (2013, p.311), que estuda uma grande varejista do comércio eletrônico que implementa práticas de LR visando ganhos de produtividade na operação. Em suas conclusões (p. 319), são citadas somente oportunidades para redução do retorno de produtos, melhoria no tempo de processamento do retorno e controle dos gastos, garantindo a efetividade dos reparos, minimização de irregularidades e agregação de valor aos produtos retornados no processo de recuperação. Ou seja, não foram citados ganhos ambientais ao evitar que materiais contaminantes, provenientes dos produtos eletrônicos, entrassem em contato com o solo, nem os ganhos sociais, decorrentes da geração de oportunidades de emprego na cadeia reversa envolvida.

Já com o Gráfico 6, observa-se que a maioria dos estudos consideraram que as práticas de LR geram lucros referentes à economia e ao meio ambiente $(35,30 \%)$. Porém, a PNRS cita que as atividades de gestão ambientalmente adequadas devem gerar lucros econômicos, ambientais e sociais. Neste sentido, torna-se imperativo desenvolver pesquisas em LR que abordem a identificação de potenciais ganhos, considerando aspectos sociais ou econômicos, de forma isolada ou integrada a fatores ambientais.

Gráfico 6 - Quais os ganhos obtidos com a prática de LR destacados no artigo?

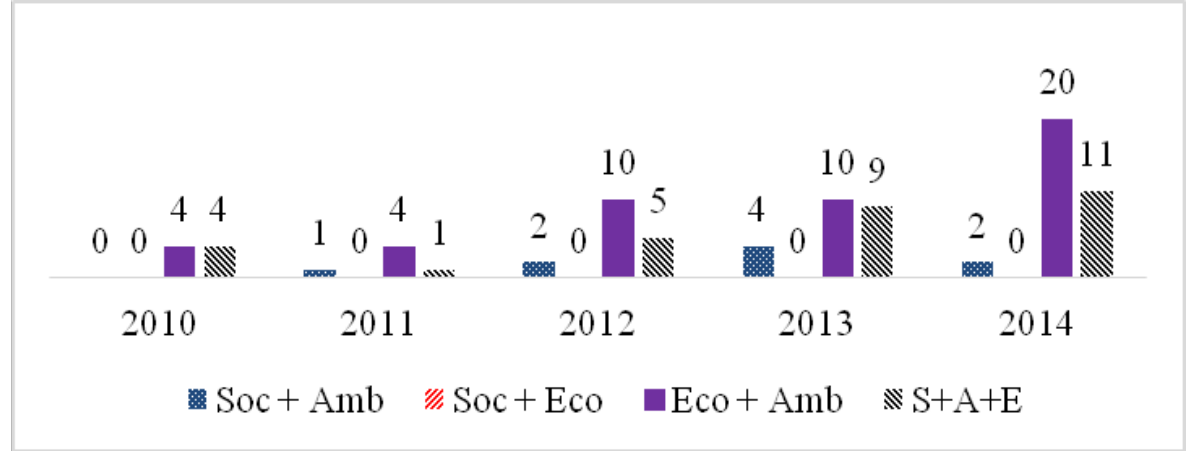

Fonte: Autores (2015)

Questão 5: Quantos artigos tratam a $L R$ de pós-venda e quantos tratam a $L R$ de pós-consumo? 
Ao propor a Questão 5, o estudo visou avaliar a frequência com que estudos e práticas de LR tem sido desenvolvidos nas organizações, sejam estes relacionados à $L R$ de pós-venda, buscando diferenciação e a fidelização dos clientes, ou relacionados à LR de pós-consumo, identificando oportunidades de revalorização do material que atingiu seu ciclo de vida útil. Fato extremamente interligado à PNRS, já que esta prevê diferentes práticas para distintos canais de distribuição reversos.

Os resultados desta questão, claramente, mostram que a maior parte dos estudos trataram da LR de pós-consumo, com 93 artigos, representando 68,30\% da amostra (ver Gráfico 7).

Assim, a maioria das publicações analisadas tratou de identificar oportunidades de reinserção de materiais (resíduos de pós-consumo) ao ciclo produtivo (fechado ou aberto), após o fim do seu ciclo de vida útil, seja por defeitos, depreciação tecnológica, entre outros fatores.

Gráfico 7 - Quantos artigos tratam da LR de pós-venda e quantos tratam LR de pós-consumo?

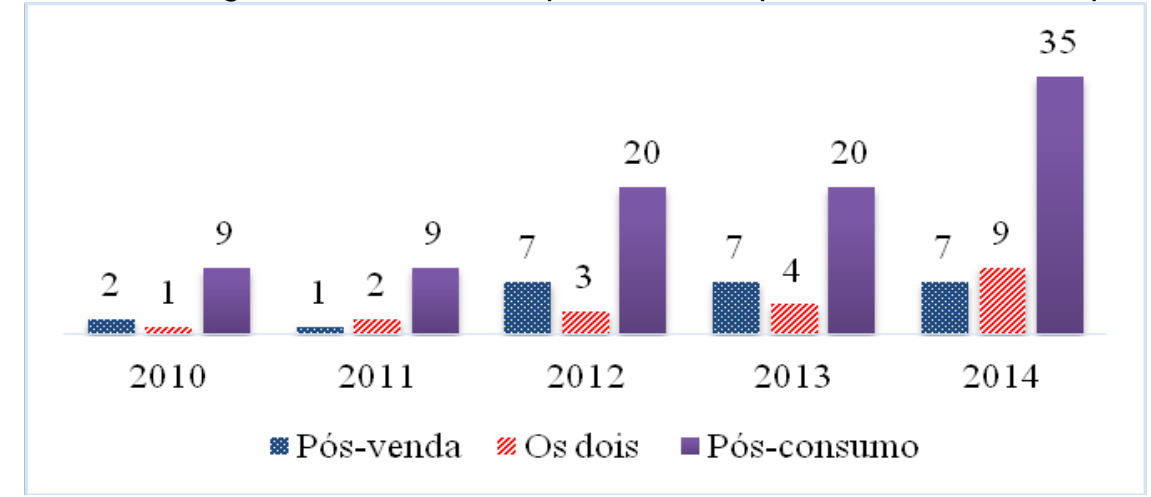

Fonte: Autores (2015)

Este resultado pode ter sido (ou, certamente ainda será) influenciado por aspectos legais, ambientais e sociais, associados à PNRS e por oportunidades econômicas, viabilizadas pela adoção de novos conceitos (p. ex.: sustentabilidade, engenharia reversa, responsabilidade compartilhada etc.) e pelos avanços tecnológicos tanto em desenvolvimento de novos materiais e processos mais sustentáveis quanto em processos de reciclagem, novos ou mais eficientes.

Quanto aos estudos sobre LR de pós-venda, ressalta-se que, apesar de em menor número, também houve crescimento, entre o segundo e o terceiro anos de análise, alcançando certa estabilidade nos anos seguintes. Tal resultado justifica-se pelo aumento da competitividade do mercado que, por sua vez, tem estimulado os 
recentes e crescentes lançamentos de novos produtos, com diferenciais e, em consequência, especificidades que exigem canais reversos igualmente específicos.

Além disso, o pós-venda é considerado um canal relativamente estruturado, já que as próprias empresas, para fidelizar clientes ou obter ganhos financeiros, oferecem algum tipo de serviço pós-venda. Dessa forma, caso o produto não atenda às expectativas do consumidor, este retorna à empresa pelo canal direto, ou pelo canal reverso criado com essa finalidade, para assim ser trocado ou outras medidas serem efetuadas. Ressalta-se que algumas empresas usam canais reversos de pósvenda para reinserir o produto no mesmo ciclo produtivo, incentivando o mercado relacionado, a partir de estratégias de marketing, como promoções.

Questão 6: Quantos artigos abordam a $L R$ de ciclo aberto e quantos abordam a $L R$ de ciclo fechado?

A LR de pós-consumo pode ser classificada como de ciclo aberto, onde o material ou resíduo é reinserido em outro ciclo produtivo, servindo de insumo base para produção de outros tipos de bens, ou de ciclo fechado, onde o material ou resíduo volta para o mesmo ciclo produtivo inicial, servindo de insumo à produção de bens iguais ou semelhantes. Assim, a Questão 6 foi proposta para identificar e avaliar os principais destinos propostos, nos artigos da amostra, aos resíduos de pós-consumo, além de identificar qual desses ciclos (aberto ou fechado) vem sendo estudado com mais frequência, por consequência, potencializando a geração de mais benefícios relacionados à cadeia e às organizações envolvidas.

Nesse contexto, no Gráfico 8, é demonstrado que a maior parte dos estudos (56 artigos - 41,20\%) analisaram a LR de ciclo aberto, resultado pode ser motivado pela crescente busca por novas fontes de insumo, mais econômicas e sustentáveis ambientalmente, sobretudo, e, geralmente, localizadas em setores menos competitivos em termos de consumo dos resíduos demandados. 
Gráfico 8 - Quantos artigos tratam da LR de ciclo aberto e quantos tratam da LR de ciclo fechado?

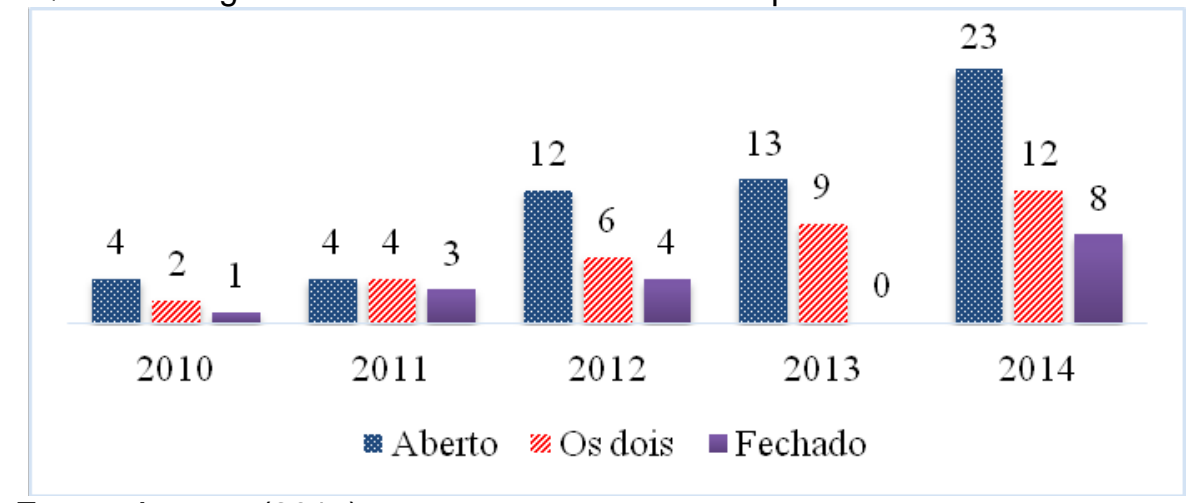

Fonte: Autores (2015)

Mesmo em menor número, os estudos que analisaram a LR de ciclo fechado, na qual o material captado é transformado em um bem com funcionalidade igual ou semelhante à inicial, também apresentaram tendência de crescimento, porém, em números absolutos, menor, considerando a amostra avaliada. Tal resultado leva a crer que também tem havido demandas por pesquisas referentes à LR de ciclo fechado, certamente na busca de estratégias ou para identificação de novas formas de reuso e reciclagem de outros resíduos, possibilitando a formação de novos canais reversos de ciclo fechado, ou para definição de alternativas de reestruturação para aumento da sustentabilidade dos canais reversos já existentes.

A razão da soma dos artigos analisados no Gráfico 8 resultar em 105, e não 136, decorreu do fato dos artigos que tratavam de LR de pós-venda não terem sido considerados, uma vez que não configuram nem ciclo aberto nem ciclo fechado.

Por meio da avaliação da evolução dos estudos de LR, dos últimos 5 anos, considerando o contexto de implementação da PNRS, a partir da análise de 136 artigos provenientes das principais fontes de publicações brasileiras associadas à Engenharia de Produção e considerando um conjunto de seis questões com objetivos de análise predefinidos, foram constatadas algumas tendências e lacunas de conhecimento sobre os estudos LR desenvolvidos nos últimos anos.

Tais informações serviram de base para a proposição de possíveis oportunidades para o desenvolvimento de novas pesquisas, voltadas ao preenchimento das lacunas de conhecimento identificadas e considerando temas relacionados à Logística, conforme apresentado no Quadro 2 que relaciona cada uma das questões propostas para avaliar a evolução de estudos sobre LR, às suas 
respectivas tendências de estudos de LR identificadas no período considerado e oportunidades para o desenvolvimento de novas pesquisas.

Quadro 2- Oportunidades para Desenvolvimento de Novas Pesquisas em Logística

\begin{tabular}{|c|c|c|}
\hline Questões Propostas & Tendências de Estudos & $\begin{array}{c}\text { Oportunidades de Novas } \\
\text { Pesquisas }\end{array}$ \\
\hline $\begin{array}{l}\text { 1) O enfoque de LR } \\
\text { considerado extrapola os } \\
\text { limites organizacionais da } \\
\text { empresa em estudo? }\end{array}$ & $\begin{array}{c}\text { Crescente para pesquisas que } \\
\text { não extrapolam os limites } \\
\text { internos }\end{array}$ & $\begin{array}{l}\text { Estudos de LR integrando } \\
\text { aspectos internos e externos, } \\
\text { voltados à identificação e } \\
\text { organização de elos, e } \\
\text { consolidação de canais } \\
\text { reversos, considerando temas } \\
\text { como RSCM, GIRS e } \\
\text { Responsabilidade } \\
\text { Compartilhada }\end{array}$ \\
\hline 2) A PNRS é citada no estudo? & $\begin{array}{c}\text { Crescente para citação da } \\
\text { PNRS }\end{array}$ & $\begin{array}{c}\text { Estudos que utilizem a PNRS } \\
\text { como base para o } \\
\text { desenvolvimento de pesquisas } \\
\text { em LR }\end{array}$ \\
\hline $\begin{array}{l}\text { 3) Quais materiais envolvidos } \\
\text { na LR são abordados no } \\
\text { artigo? }\end{array}$ & $\begin{array}{l}\text { Crescente para pesquisas } \\
\text { sobre maior diversificação de } \\
\text { materiais, em especial para } \\
\text { resíduos da construção civil, } \\
\text { hospitalares e orgânicos }\end{array}$ & $\begin{array}{l}\text { Pesquisas que considerem } \\
\text { estratégias e operações de LR } \\
\text { voltadas aos resíduos } \\
\text { considerados na PNRS }\end{array}$ \\
\hline $\begin{array}{c}\text { 4) Quais os ganhos } \\
\text { (Ambientais, Econômicos ou } \\
\text { Sociais) obtidos com a(s) } \\
\text { prática(s) de LR destacada(s) } \\
\text { no artigo? }\end{array}$ & $\begin{array}{c}\text { Crescente somente para } \\
\text { pesquisas sobre ganhos } \\
\text { ambientais }\end{array}$ & $\begin{array}{c}\text { Pesquisas em LR que } \\
\text { identifiquem os potenciais } \\
\text { ganhos nas dimensões sociais } \\
\text { ou econômicas, de forma } \\
\text { isolada ou integrada às } \\
\text { dimensões ambientais }\end{array}$ \\
\hline $\begin{array}{l}\text { 5) Quantos artigos tratam a LR } \\
\text { de pós-venda e quantos tratam } \\
\text { a LR de pós-consumo? }\end{array}$ & $\begin{array}{l}\text { Crescente para pesquisas em } \\
\text { LR de pós-consumo e } \\
\text { Crescente (primeiros anos) e } \\
\text { estável (últimos anos) para } \\
\text { pesquisas em LR de pós-venda }\end{array}$ & $\begin{array}{l}\text { Pesquisas voltadas à } \\
\text { estruturação de canais } \\
\text { reversos de pós-consumo e } \\
\text { pós-venda mais adequados às } \\
\text { especificidades de produtos }\end{array}$ \\
\hline $\begin{array}{l}\text { 6) ) Quantos artigos tratam a } \\
\text { LR de ciclo aberto e quantos } \\
\text { tratam a LR de ciclo fechado? }\end{array}$ & $\begin{array}{l}\text { Crescente para pesquisas em } \\
\text { LR de ciclo aberto e ciclo } \\
\text { fechado (em menor proporção) }\end{array}$ & $\begin{array}{c}\text { Pesquisas voltadas à } \\
\text { identificação de novas } \\
\text { alternativas de canais reversos } \\
\text { de ciclo aberto e à estruturação } \\
\text { de canais reversos de ciclo } \\
\text { fechado já existentes ou não }\end{array}$ \\
\hline
\end{tabular}

Fonte: Autores (2015)

\section{Considerações Finais}

A análise dos estudos publicados no Brasil, entre 2010 e 2014, acerca da Logística Reversa (LR), evidenciou um crescente aumento no número de publicações que discorrem sobre o tema em questão. Fato considerado positivo, uma vez que a Política Nacional de Resíduos Sólidos (PNRS) busca e incentiva práticas que tratem do meio ambiente, e tais estudos podem servir como base para

a geração de mais conhecimento tanto para as empresas como para a sociedade, Revista Produção Online, Florianópolis, SC, v.15, n. 4, p. 1457-1480, out./dez. 2015. 
de maneira geral. Porém, a influência da PNRS nos estudos desenvolvidos nos artigos da amostra avaliada, foi considerada ainda tímida, uma vez que as citações sobre PNRS se restringiram ao levantamento bibliográfico, com pouca ou nenhuma consideração desta em aplicações ou estudos de caso. Além disso, a maioria dos artigos analisados (56,60\%) nem mesmo citam a PNRS.

No que diz respeito à Responsabilidade Compartilhada, proposta pela Lei, no estudo aqui desenvolvido foi considerada pouco presente, posto que a maioria das empresas (52,20\%), entre as consideradas nos artigos analisados, não apresentaram práticas de integração com outros elos envolvidos na cadeia reversa dos resíduos, mantendo as atividades de LR somente dentro de seus limites organizacionais.

No que concerne à frequência de estudos sobre as abordagens de LR e aos destinos dados aos resíduos, os predominantes foram aqueles resultantes da LR de pós-consumo $(68,30 \%)$, onde os resíduos chegaram ao fim de seu ciclo de vida útil e foram reinseridos aos mesmos (ou semelhantes) ciclos produtivos (LR de ciclo fechado) ou, como na maioria dos artigos analisados, a diferentes ciclos produtivos (LR de ciclo aberto - 41,20\%).

Em relação às 6 classes de materiais previstas na PNRS, predominou a classe Geral (32,40\%), indicando que a maioria dos estudos ainda não têm tratado as práticas de LR considerando especificidades de cada classe de material. Além disso, ressalta-se que $30,20 \%$ dos artigos analisados abordaram materiais não contemplados em nenhuma das classes previstas na PNRS, neste estudo, então considerados na classe Outros.

Ressalta-se, ainda, que a Lei que resulta na PNRS busca gerar lucros econômicos, ambientais e sociais, porém, muitas empresas, entre as consideradas nos artigos analisados, seguem suas diretrizes somente por questões legais e deixam de usufruir de outras possibilidades que a implementação adequada desta Lei pode gerar. Fato que pôde ser constatado na Questão 4, onde a maioria das empresas consideraram que as práticas de LR só geram ganhos econômicos e ambientais (35,30\%) seguido pelos ganhos somente ambientais (25,7\%), tendo o lucro social com pouco prestígio. Ainda no que diz respeito a esse assunto, 0 reconhecimento social deveria ser mais presente, tendo em vista que a PNRS prevê a valorização de todos aqueles envolvidos nas práticas de reutilização e reciclagem 
dos resíduos, incentivando a criação e valorização das cooperativas de catadores de materiais recicláveis.

A análise dos artigos de LR, considerando a amostra estabelecida, permitiu avaliar tendências de desenvolvimento de estudos relacionados e, a partir desta, identificar lacunas de conhecimento que, por sua vez, viabilizaram a proposição de oportunidades para o desenvolvimento de novas pesquisas em LR associadas ao contexto de implementação da PNRS, permitindo, assim, que os trabalhos a ser desenvolvidos e publicados, ainda disponibilizem uma gama de possibilidades de análises e pesquisas, entre as quais somente algumas foram tratadas neste estudo.

\section{REFERÊNCIAS}

ABRELPE - Associação Brasileira de Empresas de Limpeza Pública e Resíduos Especiais. Panorama dos resíduos sólidos no brasil. Brasil: Grappa Editora e Comunicação, 2013. Disponível em: <http://www.abrelpe.org.br/Panorama/panorama2013.pdf>. Acesso em: 13 jan. 2015.

ALMEIDA, Carla da Silva. Adequação dos sistemas de gerenciamento de resíduos sólidos de uma empresa cerâmica à Política Nacional conforme Lei 12.305/2010. 2013. 1 v. TCC (Graduação) - Curso de Engenharia Ambiental, Universidade do Extremo Sul Catarinense, Criciúma, 2013.

ANDRADE, Sabrina Gimenes de. Entraves Brasil. 2013. 1 v. Tese (Doutorado) - Curso de Gestão e Regulação dos Serviços Públicos de Saneamento Básico, Escola Nacional de Saúde Pública Sergio Arouca, Rio de Janeiro, 2013. Disponível em:

<http://pesquisa.bvsalud.org/portal/resource/pt/lil-711918>. Acesso em: 27 dez. 2014

ARAÚJO, Ana Carolina de; MATSUOKA, Érica Mayumi; UNG, July Ellen; HILSDORF, Wilson de Castro; SAMPAIO, Mauro. Logística Reversa no comércio eletrônico: Um estudo de caso. Gestão \& Produção, São Carlos, v.20, p.303-320, 2013. Disponível em:< http://www.scielo.br/scielo.php?script=sci_arttext\&pid=S0104-530X2013000200005>. Acesso em: 09 fev. 2015.

ARAÚJO, Carlos Alberto. Bibliometria: evolução histórica e questões atuais. Em Questão, Porto Alegre, v. 12, p.11-32, jun. 2006. Disponível em: <http://www.revistas.univerciencia.org/index.php/revistaemquestao/article/view/3707/3495>. Acesso em: 30 jan. 2015.

ARAÚJO, Patrícia Vara Brusch. Aterro Sanitário como uma das faces da gestão integrada de resíduos sólidos urbanos: Um estudo de caso no município de Elói Mendes, MG. 2011. 146 p. Dissertação (Mestrado) - Curso de Gestão Social, Desenvolvimento Territorial e Meio Ambiente, Universidade Federal de Lavras, Lavras, 2011.

BARBIERI, José Carlos; FILHO, José Milton de Sousa; BRANDÃO, Cristiane N.; SERIO, Luiz Carlos Di; JUNIOR, Edgar Reyes. Gestão verde da cadeia de suprimentos: Análise da produção acadêmica brasileira. Produção Online, v. 14, n. 3, 2014.

http://dx.doi.org/10.14488/1676-1901.v14i3.1674 
BRASIL. Ministério do Meio Ambiente. Secretaria de Recursos Hídricos e Ambiente Urbano. Manual Para Implantação de Sistema de Apropriação e Recuperação de Custos dos Consórcios Prioritários de Resíduos Sólidos: Projeto Internacional De Cooperação Técnica Para A Melhoria Da Gestão Ambiental Urbana No Brasil Bra/Oea/08/001. Brasília, 2010b. Disponível em:

<http://www.mma.gov.br/estruturas/srhu_urbano/_arquivos/2_manual_implantao_sistema_a propriao_rec_custos_cp_rs_125.pdf>. Acesso em: 24 dez. 2014.

BRASIL. Política Nacional de Resíduos Sólidos (Lei n 12.305/2010). Brasília: Diário Oficial da União, 2010a. Disponível em: <https://www.planalto.gov.br/ccivil_03/_ato20072010/2010/lei/l12305.htm>. Acesso em: 25 dez. 2014.

CARVALHO, Marcius Fabius Henriques; FIORAVANTI, Reinaldo Daniel; JUNIOR, Orlando Fontes Lima. Modelos de cadeiras de laço fechado na indústria de impressão. Produção Online, v. 11, n. 4, 2011. http://dx.doi.org/10.14488/1676-1901.v11i4.641

CRUZ, Marcia Rohr da; Bagattini, Leonardo da Costa; Silva, José Edson Azevedo da; Xavier, Eduardo; Paris, Adriano de; Camargo, Maria Emilia. Logística Reversa na fabricação de elementos de fricção em indústria da Serra Gaúcha. Gepros. Gestão da Produção, Operações e Sistemas, Bauru, v. 3, n. 8, p.85-98, ago. 2013. Disponível em: <http://revista.feb.unesp.br/index.php/gepros/article/view/941/503>. Acesso em: 25 dez. 2014.

DIAS, Sylmara Lopes Francelino Gonçalves; LABEGALINI, Letícia; CSILLAG, João Mário. Sustentabilidade e cadeia de suprimentos: uma perspectiva comparada de publicações nacionais e internacionais. Produção, São Paulo, v. 22, n. 3, p. 517-533, maio/ago 2012. Disponível em:< http://www.scielo.br/scielo.php?script=sci_arttext\&pid=S010365132012000300012>. Acesso em: 03 fev. 2015.

DRUWE, Daiane Martin. O que a logística reversa representa hoje e para o futuro? ABEPL - Associação Brasileira de Empresas e Profissionais da Logística. Disponível em: <http://www.abepl.org.br/artigos_detalhes.php?artigo=14>. Acesso em: 24 dez. 2014.

FARIA, Andréa Guimarães de. A responsabilidade pós-consumo dos fornecedores no contexto da Política Nacional de Resíduos Sólidos. 49 p. TCC (Graduação) - Curso de Bacharelado em Direito, Universidade Estadual da Paraíba, Campina Grande, 2012.

GRAZIERA, Maria Luiza Machado. Direito Ambiental. 2 ed. Revista e atualizada. São Paulo: Atlas, 2011.

GUARNIERI, Patrícia. Logística Reversa: Em busca do equilíbrio econômico e ambiental. Recife: Clube de Autores, 2011. 307 p.

GUPTA S, VERMA R, VICTORINO, L. Empirical Research Published in Production and Operations Management (1992-2005): Trends and Future Research Directions. Production and Operations Management, v. 15, n. 3, p.432-448, 2006.

http://dx.doi.org/10.1111/j.1937-5956.2006.tb00256.x

LEITE, Paulo Roberto. Logística reversa: meio ambiente e competitividade. 2 ed. São Paulo: Pearson Prentice Hall, 2003.

LEITE, Paulo Roberto. Desafios da Logística Reversa de pós-consumo no Brasil. Revista Tecnologística, p.64-67, 2014. Disponível em:

<http://www.clrb.com.br/site/publicacoes.asp?id=202>. Acesso em: 23 dez. 2014. 
LEITE, Paulo Roberto. Direcionadores estratégicos em programas de logística reversa no Brasil. Revista Alcance, v. 19, n. 2, p. 182-201, 2012.

LIRA, André da Silva. Política nacional de resíduos sólidos: aspectos relevantes. 56 p. TCC (Graduação) - Curso de Bacharelado em Direito, Universidade Estadual da Paraíba, Campina Grande, 2010.

MAGNAGO, Patrícia Flores; AGUIAR, João Pedro Ornaghi de; PAULA, Istefani Carisio de. Sustentabilidade em desenvolvimento de produtos: Uma proposta para a classificação de abordagens. Produção Online, v.12, n. 2, 2012.

http://dx.doi.org/10.14488/1676-1901.v12i2.796

NETO, Francisco Firmino da Silva; CARMO, Breno Barros Telles do. Proposta de um modelo de coleta para o canal reverso de pós-consumo de papel em um campus universitário baseado na teoria dos grafos. Produção Online, v. 13, n. 4, 2013. http://dx.doi.org/10.14488/1676-1901.v13i4.1526

NOVAES, Bruna Prado de; SILVA, Lanaira da. Dos sistemas de disposições de resíduos sólidos na sociedade pós-consumo:: uma análise da Lei 12.305/2010 e seus reflexos nas cooperativas de material reciclável no município de Maringá/PR. Planeta Amazônia:

Revista Internacional de Direito Ambiental e Políticas Públicas, Macapá, v. 1, n. 5, p.5970, 10 jul. 2013. Disponível em:

<http://periodicos.unifap.br/index.php/planeta/article/viewArticle/1051>. Acesso em: 22 dez. 2014.

RAMALHO, Susan Catieri; SELLITTO, Miguel Afonso. Avaliação do desempenho ambiental de uma empresa de tratamento superficial de alumínio. Produção Online, v.13, n. 3, 2013. http://dx.doi.org/10.14488/1676-1901.v13i3.1357

REVERSE LOGISTICS EXECUTIVE COUNCIL. What is Reverse Logistics?. Disponível em: <http://www.rlec.org/glossary.html>. Acesso em: 27 dez. 2014.

SILVA, Giuliana Paduan; BARROS, Sônia Regina Pereira Faria. O impacto da Política Nacional de Resíduos Sólidos no âmbito empresarial. In: INCITEL 2012 - Congresso de Iniciação Científica no Inatel, Santa Rita do Sapucaí, MG, p.223-228, 2012.

TENÓRIO, Fernando Antônio Guimarães; SILVA, Débora Eleonora Pereira da; DACORSO, Antônio Luiz Rocha. Inovação e tomada de decisão no processo de logística reversa: Uma análise bibliométrica. Produção Online, v. 14, n. 2, 2014.

http://dx.doi.org/10.14488/1676-1901.v14i2.1434

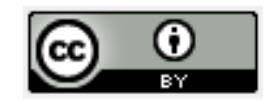

Artigo recebido em 05/03/2015 e aceito para publicação em 16/09/2015

DOI: http://dx.doi.org/ 10.14488/1676-1901.v15i4.2006 